\title{
Çoklu Melez Parsellerinde Yer Alan Yonca Genotiplerinin Tohum Tutma Özelliklerinin Belirlenmesi
}

\author{
Emre BIÇAKÇI ${ }^{*}$, Cahit BALABANLI ${ }^{1}$
}

${ }^{1}$ Süleyman Demirel Üniversitesi, Ziraat Fakültesi, Tarla Bitkileri Bölümü, Isparta

(Alınış / Received: 05.04.2016, Kabul / Accepted: 25.07.2016, Online Yayınlanma / Published Online: 06.09.2016)

\section{Anahtar Kelimeler}

Yonca,

Tohum verimi,

Göller yöresi
Özet: Bu araștırma, göller yöresinden toplanmış 10 adet yonca (Medicago sativa L.) genotipinde tohum tutma özellikleri ve bazı verim unsurlarını belirlemek amacıyla 2014 yllında Süleyman Demirel Üniversitesi Ziraat Fakültesi deneme arazisinde yürütülmüştür. Araștırmada kullanılan bitkisel materyaller içerisinde, en uzun bitki boyu $(103.22 \mathrm{~cm}) 6$ nolu genotipten, en yüksek bitkide sap sayısı (55.44 adet/bitki), salkımda çiçek sayısı (62.33 adet) ve bitki başına tane verimi (78.94 g) 2 nolu genotipten, en fazla salkımda meyve sayısı (40.77 adet) 3 nolu genotipten, en iyi meyve/çiçek oranı (\%80) ve bin tane ağırlı̆̆ı (1.93 g) 4 numaralı genotipten ve en yüksek meyvede tane sayısı (5.56 adet) 9 nolu genotipten elde edilmiştir. Verime etki eden faktörler bakımından 2, 3, 4 ve 6 numaralı genotiplerin diğer genotiplere oranla daha iyi durumda oldukları belirlenmiștir.

\section{Determination of Seed Set Characteristics of Alfalfa Genotypes are Planted in Polycross Parcels}

\section{Keywords}

Alfalfa,

Seed yield,

Region of lakes

\begin{abstract}
This research was conducted to determine seed set and some yield characteristics of 10 alfalfa genotypes collected from lakes region in experiment area of Suleyman Demirel University Agriculture Faculty in 2014 year. In the research, the highest plant length $(103.22 \mathrm{~cm})$ were obtained from the number 6 genotype, the highest stem numbers per plant (55.44 pieces/plant), floret numbers per raceme (62.33 floret/raceme) and seed yields per plant (78.94 g) from the number 2 genotype, pod numbers per raceme (40.77 pod/raceme) from the 3 number genotype, the rate of pod/raceme $(\% 80)$, the 1000 seed weight $(1.93 \mathrm{~g})$ from the number of 4 genotype and the seed number per pod (5.56 seed/pod) form the 5 number genotype. The lowest values of these characteristics varied according to genotypes.
\end{abstract}

\section{Giriş}

Dünyada ve ülkemizde üretimi en fazla tercih edilen yem bitkileri arasında ilk sırayı yonca almaktadır. Bunun başlıca sebepleri yoncanın, yüksek yem değerine ve geniş adaptasyon yeteneğine sahip olması, rhizobium bakterileri sayesinde toprağa azot bağlaması ile özellikle yabani arılar için polen kaynağı olmasıdır. Yonca genellikle, kuru ot üretimi, otlatma ve silo yemi yapmak amacıyla yetiştirilir[1]. Birim alan protein verimi de yüksek olan yoncanın kuru ve yeșil otu her türlü hayvan için lezzetli ve besleyicidir. Yonca \%15-22 oranında ham protein içermesinin yanı sıra mükemmel bir mineral ve vitamin kaynağıdır. A, D, E, K, U, C, B1, B2, B6, B12, niasin, pantotenik asit, inositol, biotin, folik asit vb. gibi birçok vitaminin yanında fosfor, kalsiyum, potasyum, sodyum, klor, sülfür, magnezyum, bakır gibi pek çok mineral maddeyi de bünyesinde bulundurmaktadır. Yonca, zengin kimyasal kompozisyonu ile hayvan beslemede büyük önem taşımaktadır [2;3].

Çukurova koşullarında yapılan bir çalıșmada yonca klon hatlarının ortalama bitki boylarının 73.00-95.00 $\mathrm{cm}$ arasinda, polycross denemesinde ise $74-79 \mathrm{~cm}$ arasında değiștiği [4]; İzmir'de yürütülen bir araștırmada yonca hatlarının bitki boylarının ortalama $92.26-115.58 \mathrm{~cm}$ ve kuru ot verimlerinin 1182.00-2066.00 kg/da arasında olduğu [5]; Ankara'da elçi yonca klonlarının tohum teşekkülü ve seçilen klonların ileriki döllerinde yeșil yem üretimine etki eden faktörler üzerinde yapılan bir 
çalışmada, çeşitlerin bitki boylarının 59.80-121.00 cm arasında değişim gösterdiği [6] bildirilmiştir.

$\mathrm{Bu}$ çalışma, göller yöresinden toplanmış ve klonla çoğaltılmış 10 farklı yonca genotipinin, bazı morfolojik ve tohum tutma özelliklerinin belirlenmesi amacı ile yapılmıştır.

\section{Materyal ve Metot}

\subsection{Materyal}

Çalışmanın materyalini oluşturan yonca genotipleri Isparta, Burdur, Afyon ve Konya illerine bağlı 22 ilçede toplam 60 farklı duraktan 2010 yılında klon olarak toplanmıștır. 3 yıl boyunca 60 popülasyonda fenolojik, morfolojik, verim ve kalite analizlerinin yanı sıra moleküler karakterizasyon çalışmaları yapılmıştır. Üçüncü yılın sonunda incelenen karakterler yönünden üstün özellikler gösteren ve moleküler karakterizasyon bakımından da farklılık arz eden 10 yonca popülâsyonu (Eğirdir-2, Yalvaç-3, Bolvadin-1, Senirkent-2, Yeşilova-3, Beyşehir-2, Çay1, Sultandağl-2, Şarkikaraağaç-3 ve Yenişar-1) çoklu melez parsellerini oluşturmak amacıyla seçilmiştir.

Tarla toprağı; tekstür bakımından killi-kalkerli, alkali (pH değeri 8.1), katyon değişim kapasitesi \%36.00 ve toplam tuz içeriği \%0.025 olan, kireççe zengin (\%25.50), elverişli fosfor bakımından fakir $(3.55$ $\mathrm{P}_{2} \mathrm{O}_{5} / \mathrm{da}$ ), potasyum bakımından zengin (75.40 $\mathrm{K}_{2} 0 / \mathrm{da}$ ), organik madde bakımından fakir (\%1.34) ve yarayışlı nem (\%8.35) bakımından yetersiz bir topraktır.

Araştırmanın yürütüldüğü yıllar ve uzun yıllar ortalamasına ait aylık ortalama nispi nem, yağış ve sıcaklığa ilişkin değerler Tablo 1.'de sunulmuştur.

\subsection{Metot}

Seçilen 10 yonca genotipi sera koşullarında klon olarak çoğaltıldıktan sonra 2013 yılı ağustos ayında tesadüf blokları deneme desenine göre 4 tekerrürlü olarak 1 x $1 \mathrm{~m}$ aralıklı olarak araziye şaşırtılarak polycross parselleri oluşturulmuştur.

2014 yılı Mayıs ayının üçüncü haftasında tüm bitkiler ot olarak biçilmişlerdir. Bu işlemin amacı tozlaşmanın daha etkin olmasını sağlayan arı faaliyetlerinin daha aktif olduğu Haziran-Ağustos ayları arasında bitkilerden daha fazla tohum elde etmektir. Çiçeklenme başlangıcı döneminde çoklu melez parsellerinin içerisine bir adet bombus arı kovanı koyularak tozlaşmanın daha etkin olması sağlanmıştır.

Çoklu melez parsellerinde bitki boyu, sap sayısı, salkımda çiçek sayısı, salkımda meyve sayısı, meyve/çiçek oranı, bitki başına tane verimi, bin tane ağırlığı, meyvede kıvrım sayısı, meyvede tane sayısı gibi ölçüm ve gözlemler yapılmıştır [6].

Tesadüf blokları deneme desenine göre yürütülen denemeden elde edilen veriler SAS 9.0 bilgisayar programından yararlanılarak Duncan testine göre varyans analizi yapılmıștır.

\section{Araştırma Bulguları ve Tartışma}

Genotiplerin bitki boyu, sap sayısı, salkımda çiçek sayısı, salkımda meyve sayısı, meyve/çiçek oranı, bitki başına tane verimi, bin tane ağırlığı, meyvede kıvrım sayısı ve meyvede tane sayısı farklılıklar oluşmuştur (Tablo 2).

Bitki boyu bakımından 6 numaralı genotip $103.22 \mathrm{~cm}$ ile en uzun boylu genotip olarak tespit edilmiştir. Bunu $99.77 \mathrm{~cm}$ ile 8 numaralı genotip ve $96.167 \mathrm{~cm}$ ile 1 numaralı genotip takip etmiştir. Genotiplerin genel bitki boyu ortalaması $92.49 \mathrm{~cm}$ olarak tespit edilmiştir. Elde edilen sonuçların ortalaması, Akbari ve Avcioğlu [7]'nun belirttiği değerler ile uyum gösterirken, Şeker ve ark. [8] ile Gülcan [9]'ın belirttiği değerlerden yüksek bulunmuştur.

Sap sayısı yoncada kaba yem verimini etkileyen ana unsurlardan birisidir ve yoncada sap sayısının düşük veya yüksek oluşunun genetik ve çevresel faktörlerle birim alandaki bitki sayısına bağlı olduğu bilinmektedir.

Genotipler arasında bitki başına en fazla sap sayısı 55.44 adet ile 2 numaralı genotipte belirlenmiş, bunu 4 numaralı genotip (35.67 adet/bitki) ve 3 numaralı (34.44 adet/bitki) genotip takip etmiștir. 10 adet genotipin genel ortalaması 31.81 adet/bitki olarak tespit edilmiştir. Elde edilen sonuç, Petkova ve ark. [10]'nın belirttiği sonuçla örtüşürken, Şengül [11]'in belirttiği değerin biraz üzerinde bulunmuștur.

Yonca genotiplerinin arasında en yüksek salkımda çiçek sayısı 62.33 adet ile 2 numaralı ve 60.11 adet ile 3 numaralı genotiplerde tespit edilmiş olup 8 numaralı genotipi de (49.33 adet) aynı gruba girmiștir. Genotiplerin genel ortalaması 43.62 adet çiçek/salkım olarak tespit edilmiştir. $\mathrm{Bu}$ sonuç Tamkoç [12]'un Ankara sulu şartlarında yaptığı çalışmadan elde ettiği değerler ile benzerlik göstermektedir.

Genotipler arasında salkımda meyve sayısı bakımından en yüksek değer 40.77 adet/salkım ile 3 numaralı genotipte ve 35.55 adet/salkım ile 2 numaralı genotipte tespit edilmiştir. Genotiplerin genel ortalaması 30.21 adet meyve/salkım olarak belirlenmiş, elde edilen bu değerler Tamkoç [12], Tamkoç [13] ile Karakurt ve Firıncıoğlu [14]'nun belirttiği değerlerden yüksek bulunmuştur. 
Tablo 1. Deneme yılına ait iklim verileri

\begin{tabular}{|c|c|c|c|c|c|c|c|c|c|}
\hline \multirow[b]{2}{*}{ Aylar } & \multicolumn{3}{|c|}{ Uzun Yıllar } & \multicolumn{3}{|c|}{2013} & \multicolumn{3}{|c|}{2014} \\
\hline & $\begin{array}{c}\text { Sicaklık } \\
\left({ }^{\circ} \mathrm{C}\right)\end{array}$ & $\begin{array}{c}\text { Aylık Top. } \\
\text { Yağış } \\
\text { (mm) } \\
\end{array}$ & $\begin{array}{l}\text { Aylık Ort. } \\
\text { Nispi Nem } \\
(\%)\end{array}$ & $\begin{array}{c}\text { Sicaklık } \\
\left({ }^{\circ} \mathrm{C}\right)\end{array}$ & $\begin{array}{c}\text { Aylık Top. } \\
\text { Yağış } \\
(\mathrm{mm}) \\
\end{array}$ & $\begin{array}{l}\text { Aylık Ort. } \\
\text { Nispi Nem } \\
(\%)\end{array}$ & $\begin{array}{l}\text { Sicaklık } \\
\left({ }^{\circ} \mathrm{C}\right)\end{array}$ & $\begin{array}{c}\text { Aylık Top. } \\
\text { Yağış } \\
(\mathrm{mm}) \\
\end{array}$ & $\begin{array}{c}\text { Aylık Ort. } \\
\text { Nispi Nem } \\
(\%)\end{array}$ \\
\hline Ocak & 1.9 & 72.4 & 73.1 & 2.8 & 58.6 & 72.5 & 3.7 & 61.3 & 76.7 \\
\hline Şubat & 2.8 & 65.5 & 70.4 & 4.9 & 101.9 & 70.6 & 5.2 & 23.4 & 60.8 \\
\hline Mart & 6.1 & 53.8 & 65.4 & 7.3 & 25.1 & 59.7 & 7.3 & 78.6 & 63.3 \\
\hline Nisan & 10.7 & 56.2 & 61.3 & 12.1 & 59.9 & 56.5 & 11.7 & 44.8 & 59.5 \\
\hline Mayıs & 15.6 & 50.4 & 57.4 & 18.0 & 66.5 & 50.4 & 15.1 & 107.0 & 60.3 \\
\hline Haziran & 20.2 & 29.6 & 51.2 & 21.0 & 34.4 & 47.4 & 20.0 & 42.8 & 49.8 \\
\hline Temmuz & 23.6 & 14.9 & 45.4 & 23.5 & 88.2 & 41.5 & 24.5 & 0.8 & 43.5 \\
\hline Ağustos & 23.2 & 10.5 & 46.4 & 24.1 & 15.4 & 39.1 & 24.9 & 10.2 & 44.2 \\
\hline Eylül & 18.6 & 15.4 & 51.9 & 18.9 & 3.0 & 43.3 & 18.4 & 99.2 & 58.6 \\
\hline Ekim & 12.9 & 37.6 & 62.0 & 10.7 & 104.0 & 54.0 & 12.9 & 57.1 & 64.7 \\
\hline Kasım & 7.4 & 46.5 & 68.5 & 8.7 & 67.6 & 65.5 & 6.8 & 37.0 & 69.2 \\
\hline Aralık & 3.4 & 84.5 & 74.7 & 1.0 & 29.4 & 64.2 & 6.0 & 108.6 & 75.2 \\
\hline Ort. Sicaklık & 12.2 & & & 12.75 & & & 13.04 & & \\
\hline Toplam Yağış & & 537.3 & & & 654 & & & 670.8 & \\
\hline Ort. Nem & & & 60.64 & & & 55.39 & & & 60.48 \\
\hline
\end{tabular}

Tablo 2. Yoncada incelenen özelliklere ait ortalama değerler

\begin{tabular}{|c|c|c|c|c|c|c|c|c|c|c|}
\hline & Genotipler & $\begin{array}{l}\text { Bitki boyu } \\
(\mathrm{cm})\end{array}$ & $\begin{array}{c}\text { Sap sayısı } \\
\text { (adet/ } \\
\text { bitki) }\end{array}$ & $\begin{array}{c}\text { Salkımda } \\
\text { çiçek } \\
\text { sayısı } \\
\text { (adet) }\end{array}$ & $\begin{array}{l}\text { Salkımda } \\
\text { meyve } \\
\text { sayısı } \\
\text { (adet/ } \\
\text { salkım) }\end{array}$ & $\begin{array}{c}\text { Meyve/ } \\
\text { Çiçek } \\
\text { oranı (\%) }\end{array}$ & $\begin{array}{l}\text { Bitki tane } \\
\text { verimi } \\
\text { (gram/ } \\
\text { bitki) }\end{array}$ & $\begin{array}{l}\text { Bin tane } \\
\text { ağırlığı } \\
\text { (gram) }\end{array}$ & $\begin{array}{l}\text { Meyvede } \\
\text { kıvrım } \\
\text { sayıları } \\
\text { (adet/ } \\
\text { meyve) } \\
\end{array}$ & $\begin{array}{c}\text { Meyvede } \\
\text { tane } \\
\text { sayısı } \\
\text { (adet/ } \\
\text { meyve) }\end{array}$ \\
\hline 1 & Eğirdir-2 & $96.17 \mathrm{ab}$ & $24.67 \mathrm{~cd}$ & $42.17 \mathrm{bc}$ & $32.50 \mathrm{bc}$ & $0.77 \mathrm{a}-\mathrm{c}$ & $43.50 \mathrm{c}$ & $1.70 \mathrm{de}$ & $2.32 \mathrm{bc}$ & 4.89 \\
\hline 2 & Yalvaç-3 & 94.89 a-c & $55.44 \mathrm{a}$ & $62.33 \mathrm{a}$ & $35.55 \mathrm{ab}$ & $0.69 \mathrm{~cd}$ & $78.94 \mathrm{a}$ & $1.73 \mathrm{c}-\mathrm{e}$ & $2.53 \mathrm{ab}$ & 5.44 \\
\hline 3 & Bolvadin-1 & 86.78 c-e & $34.44 \mathrm{~b}$ & $60.11 \mathrm{a}$ & 40.77 a & $0.70 \mathrm{~b}-\mathrm{d}$ & $52.98 \mathrm{bc}$ & $1.7 \mathrm{de}$ & $2.02 \mathrm{~d}$ & 4.98 \\
\hline 4 & Senirkent-2 & $91.33 \mathrm{~b}-\mathrm{d}$ & $35.67 \mathrm{~b}$ & $35.50 \mathrm{bc}$ & 29.00 c-e & $0.82 \mathrm{a}$ & $64.85 \mathrm{~b}$ & $1.93 \mathrm{a}$ & $2.47 \mathrm{ab}$ & 5.02 \\
\hline 5 & Yeşilova-3 & $82.77 \mathrm{de}$ & $28 \mathrm{~b}-\mathrm{d}$ & $28.55 \mathrm{c}$ & $22.89 \mathrm{e}$ & $0.80 \mathrm{ab}$ & $53.03 \mathrm{bc}$ & $1.70 \mathrm{de}$ & $2.71 \mathrm{a}$ & 4.78 \\
\hline 6 & Beyșehir-2 & $103.22 \mathrm{a}$ & 29.22 b-d & 37.11 bc & $26.11 \mathrm{de}$ & $0.70 \mathrm{a}-\mathrm{c}$ & $44.10 \mathrm{c}$ & $1.81 \mathrm{bc}$ & $2.35 \mathrm{~b}$ & 4.28 \\
\hline 7 & Çay-1 & $80.33 \mathrm{e}$ & $24.17 \mathrm{~d}$ & $37.33 \mathrm{bc}$ & $25.33 \mathrm{de}$ & 0.68 c-e & $49.78 \mathrm{c}$ & $1.64 \mathrm{e}$ & $2.51 \mathrm{ab}$ & 5.13 \\
\hline 8 & Sultandağı-2 & $99.77 \mathrm{ab}$ & $25.33 \mathrm{~cd}$ & $49.33 \mathrm{ab}$ & $29.67 \mathrm{~b}-\mathrm{d}$ & $0.61 \mathrm{de}$ & $64.30 \mathrm{~b}$ & $1.88 \mathrm{ab}$ & $2.36 \mathrm{~b}$ & 4.70 \\
\hline 9 & Ş.karaağaç-3 & 94.50 a-c & $28.33 \mathrm{~b}-\mathrm{d}$ & $41.50 \mathrm{bc}$ & 28.83 c-e & $0.58 \mathrm{e}$ & $52.01 \mathrm{bc}$ & $1.76 \mathrm{~cd}$ & $2.07 \mathrm{~cd}$ & 5.56 \\
\hline \multirow[t]{3}{*}{10} & Yenişari-1 & 95.11 a-c & $32.88 \mathrm{bc}$ & $42.22 \mathrm{bc}$ & $31.44 \mathrm{~b}-\mathrm{d}$ & $0.76 \mathrm{a}-\mathrm{c}$ & $52.24 \mathrm{bc}$ & $1.81 \mathrm{bc}$ & $2.27 \mathrm{~b}-\mathrm{d}$ & 4.99 \\
\hline & VK (\%) & 5.65 & 15.8 & 20.98 & 12.23 & 8.64 & 13.91 & 7.72 & 6.53 & 14.47 \\
\hline & F değeri & $5.79^{* *}$ & $10.11^{* *}$ & $4.13^{* *}$ & $5.97^{* *}$ & $4.87^{* *}$ & $5.89 * *$ & $7.06^{* *}$ & $5.46^{* *}$ & 0.77 \\
\hline
\end{tabular}

**; 0,01 düzeyinde farklılı̆̆ ifade etmektedir.

Genotipler arasında en yüksek meyve/çiçek oranının $\% 82.00$ ile 4 numaralı genotipte, ardından \% 80.00 ile 5 numaralı genotipte tespit edildiği görülmektedir. Çalışmamızdaki tüm genotiplerin meyve/çiçek oranı ortalaması \% 70.00 olarak bulunmuştur.

Bitki başına en yüksek tane verimi $78.94 \mathrm{~g} /$ bitki ile 2 numaralı genotipte belirlenmiștir. Genotiplerin bitki başına ortalama tane verimi $55.57 \mathrm{~g} /$ bitki olarak bulunmuştur. Bitki başına tane verimi bakımından 78.94 g ile 2 numaralı genotipin birinci sırada yer aldığı görülmüştür. Bu durum 2 numaralı genotipin salkımda çiçek sayısı bakımından salkımda meyve sayısı yönünden üst sıralarda yer almasından kaynaklanmış olabilir. Bu değerler Tamkoç [12]'un bildirdiği değerlerden düşük, Güloğlu [15]'nun ve Avcı ve ark. [16]'nin belirttiği değerlerden yüksek bulunmuştur.

Bin tane ağırlıkları bakımından en yüksek değer 1.93 g ile 4 numaralı genotipten elde edilirken, bunu 1.88 g ile 8 numaralı genotip takip etmiştir. Genotiplerden elde edilen bin tane ağırlıkları ortalaması $1.77 \mathrm{~g}$ olarak bulunmuştur. Bulgularımız Manga [17] ve Tysdal [18]'ın bildirdiği sonuçlar ile uyum göstermektedir.

Yonca genotipleri arasında meyvede kıvrım sayıları bakımından en yüksek değer; $2.71 \mathrm{kıvrım/meyve} \mathrm{ile}$ 5 numaralı genotipte, tespit edilmiş olup bunu aynı 
gruba giren 2, 7 ve 4 numaralı genotipler takip etmiștir. 10 adet genotipin genel ortalaması 2.36 kıvrım/meyve olarak bulunmuștur.

Araştırmadan elde ettiğimiz sonuçlar ile bazı araştırıcıların bildirdikleri bulgular arasındaki farklılıklar birim alandaki bitki sayısından, bitkide sap sayısından [9], bitki büyüme hızından [20], bitkilerin döllenme şeklinden [12], biçim sayısından, iklim koşullarından, toprak yapısından [21] ve kullanılan materyallerin genetik özelliklerinden [13] kaynaklanmış olabilir.

\section{Sonuç}

Yürüttüğümüz çalışmada en yüksek sap sayısı 55.44 adet/bitki ile 2 numaralı genotipte tespit edilmiştir. Verime etki eden faktörler bakımından genotipler incelendiğinde 2, 3, 4 ve 6 numaralı genotiplerin ön plana çıktığı görülmektedir. Daha sağlıklı sonuçlar alabilmek için bu çalışmaların önümüzdeki yıllarda da devam etmesinin yararlı olacağı kanısına varılmıştır.

\section{Teşekkür}

Bu araştırmayı ÖYP05580-YL-14 nolu proje ile mali olarak destekleyen Süleyman Demirel Üniversitesi Öğretim Üyesi Yetiştirme Birim Başkanlığına ve 1100257 numaralı proje kapsamında çalışmamızda kullandığımız materyallerin teminini sağlayan TÜBİTAK'a teşekkür ederim.

\section{Kaynakça}

[1] Elçi S., Açıkgöz E. 1994. Baklagil ve Buğdaygil Yem Bitkileri Tanıtma Kılavuzu TİGEM Yayınları, 240s.

[2] Putnam, D., Russelle, M., Orloff, S., Kuhn, J., Fitzhugh, L., Godfrey, L., Kiess, A., Long, R. 2001. Alfalfa, Wildlife, and the Environment: The Importance and Benefits of Alfalfa in the 21st Century. California Alfalfa and Forage Association 36 Grande Vista, Novato, CA 94947.

[3] Hanson, A. A., Barnes, D. K., Hill, R. R. 1988. Alfalfa and Alfalfa Improvement, The American Society of Agronomy, Monograph No:29, ISBN 089118-094-X.

[4] Gülcan, H., Anlarsal, A. E. 1988. Çukurova Koşullarına Uygun Yonca Çeşit Islahı Üzerinde Araştırmalar. Çukurova Üniversitesi, Ziraat Fakültesi Dergisi, 3(2), 89-99.

[5] Avcıŏglu, R., Yıldırım, M. B., Budak, N. 1989. Ege Bölgesine Uygun Yonca Hatlarının Geliștirilmesi ve Adaptasyonu, Ege Üniversitesi Araştırma Fonu, Proje No: 1987-154, İzmir.

[6] Sevimay, C. S. 1992. Ankara Koşullarında Elçi Yonca Klonlarının Tohum Teşekkülü ve Seçilen
Klonların İleriki Döllerinde Yeşil Yem Üretimine Etki Eden Faktörler. Ankara Üniversitesi Fen Bilimleri Enstitüsü, Doktora Tezi, 174s, Ankara.

[7] Akbari, N., Avcıoğlu, R. 1992. Ege Bölgesine Uygun Bazl Yonca (Medicago sativa L.) Çeşitlerinin Agronomik Özellikleri ile Yem Kaliteleri Üzerinde Bir Araştırma, Ege Üniversitesi, Fen Bilimleri Enstitüsü, Doktora Tezi, Bornova, 132s, İzmir.

[8] Şeker, H., Tahtacioglu, L., Aygün, C. 2003. Doğu Anadolu Yoncasından Elde Edilen Hatların Kayseri ve Bilensoy-80 Çeşitleriyle Karşılaştırılmalı Genel Mahsül Büyüme Oranları ve Bazl Morfolojik Özellikler. Atatürk Üniversitesi, Ziraat Fakültesi Dergisi, 34(4), 303307.

[9] Gülcan, H. 1980. Çukurova Koșullarında Medicago sativa L., Medicago media Pers. ve Medicago orientaliss sp. anatolica Türlerinden Yonca çeșitlerinde bazı önemli bitkisel özellikler Yönünden Varyasyon ve İlişkiler Üzerinde Araştırmalar. (Basılmamış Doçentlik Tezi), Çukurova Üniversitesi, Fen Bilimleri Enstitüsü, Adana.

[10] Petkova, D., Vlahova, M., Marinova, D., Atanasov, A. 2003. Breeding Evaluation Of Transgenic Lucerne, Optimal Forage Systems For Animal Production And Environment. 12 ${ }^{\text {th }}$ Symposium European Grassland Federation, 26-28 May, Pleven/Bulgarian, 330-332.

[11] Şengül, S. 1995. Van yöresinde Yetiștirilen Yonca (Medicago sativa L.) Ekotiplerinde Bazı Morfolojik ve Sitolojik Özelliklerin İncelenmesi. Atatürk Üniversitesi, Fen Bilimleri Enstitüsü, Doktora Tezi, 111s, Erzurum.

[12] Tamkoç, A. 1985. Kayseri Yoncası Seçme Klonlarında Tohum Teșekkülü Bakımından Farkların Belirlenmesi. Basılmamış Yüksek Lisans Tezi, Selçuk Üniversitesi, Konya.

[13] Tamkoç, A. 1992. Kayseri yoncasında Seçme Elçi klonlarının Konya Şartlarında Diğer Varyetelerle Karşılaştırılması. Selçuk Üniversitesi, Fen Bilimleri Enstitüsü, Doktora Tezi, 64s, Konya.

[14] Karakurt, E., Fırıncıoğlu, H. K. 2005. Farklı Kaynaklardan Sağlanan Yonca (Medicago sativa L.) Populasyonunda Bazı Önemli Özellikler ve Özellikler Arası İlişkiler. Türkiye VI. Tarla Bitkileri Kongresi, 5-9 Eylül 2005, Antalya, 857862.

[15] Güloğlu, D. 2009. Kayseri Yoncası Hatlarının Tohum Tutma Özellikleri ve Bunların Polikros Döllerinde Yeșil Yem Veriminin Belirlenmesi. Ankara Üniversitesi, Fen Bilimleri Enstitüsü, Doktora Tezi, 90s, Ankara.

[16] Avcl, M., Hatipoğlu, R., Yücel, H., Gültekin, R., 2010. Tozlayıcı Arıların Yonca (Medicagosativa 
L.) Klon Hatlarının Meyve ve Tohum Tutmasına Etkisi. Kafkas Üniversitesi Veteriner Fakültesi Dergisi, 16(Supplement B), 305-311.

[17] Manga, İ. 1979. Erzurum Ekolojik Koşullarında Yetişebilen Önemli Yonca Varyetelerinin Bazı Agronomik Morfolojik ve Biyolojik Özellikleri Üzerinde Araştırmalar. Atatürk Üniversitesi, Ziraat Fakültesi, Doktora Tezi, 43s, Erzurum.

[18] Tysdal, H. M. 1946. Influence of Tripping, Soil Moisture, Plant Spacing and Lodging on Alfalfa Seed Production. 1946 Annual Meting in Omaha, Nebraska. November 19 to 22. Journal American Society Of Agronomy, 38(6), 515-535.

[19] Volanec, J. J., Cherney, J. H., Jonnson, K. D. 1987. Yield Components, Plant Orphology and Forage Quality of Alfalfa as Influenced by Plant Population. Crop Science, 27, 321-326.

[20] Etzel, M. G., Volenec, J. J., Vorst, J. J. 1988. Leaf Morphology, Shoot Growth, and Gas Exchange of Multifoliate Alfalfa Phenotypes. Crop Science, 28, 263-269.

[21] Elçi, Ş., Kolsarıcı, Ö. Geçit, H. H. 1994. Tarla Bitkileri, 2. Baskı Atatürk Üniversitesi Ziraat Fakültesi Yayınları 1385. Ders Kitabı:399, 163238. 